Вестник Костромского государственного университета. Серия: Педагогика. Психология. Социокинетика. 2021. T. 27, № 1. C. 46-52. ISSN 2073-1426

Vestnik of Kostroma State University, 2021, vol. 27, № 1, pp. 46-52. ISSN 2073-1426

Научная статья

УДК 159.923

https://doi.org/10.34216/2073-1426-2021-27-1-46-52

\title{
ЭМПИРИЧЕСКОЕ ИССЛЕДОВАНИЕ ВЛИЯНИЯ ЦЕННОСТНО-СМЫСЛОВОЙ СФЕРЫ ЛИЧНОСТИ НА ЕЕ ВИРТУАЛЬНЫЙ ОБРАЗ: КОМПОНЕНТ СМЫСЛОЖИЗНЕННЫХ ОРИЕНТАЦИЙ
}

Зекерьяев Руслан Ильвисович, Крымский инженерно-педагогический университет, Симферополь, Россия, rzekeryayev@inbox.ru, https://orcid.org/0000-0001-8594-127X

Аннотация. Статья посвящена исследованию влияния ценностно-смысловой сферы личности, а именно смысложизненных ориентаций, на ее виртуальный образ в интернет-пространстве. В работе осуществлен критический анализ литературы, посвященной исследованиям ценностно-смысловой сферы личности и виртуальной личности в интернет-пространстве. Ценностно-смысловая сфера характеризуется как комплексный динамический конструкт личности, который определяет ее внутренний мир и задаёт вектор ее деятельности. Также в ходе анализа литературы было выявлено, что система смыслов и ценностей детерминирует выбор поведенческих паттернов личности, а также выступает в роли цензора для оценки событий и явлений, с которыми она сталкивается. В ходе исследования проанализирована виртуальная личность интернет-пользователя как психологический феномен; описаны такие свойства виртуальной личности, как виртуальность (степень принятия виртуальной реальности как среды, в которой осуществима социальная жизнедеятельность), вовлеченность (уровень владения информационно-компьютерными технологиями и ощущение принадлежности к виртуальному социуму) и направленность (наличие или отсутствие представлений о социально одобряемом поведении в интернет-социуме). В статье также проанализированы результаты эмпирического исследования влияния компонента смысложизненных ориентаций ценностно-смысловой сферы личности на свойства ее виртуального образа.

Ключевые слова: ценностно-смысловая сфера личности, смысложизненные ориентации, результат жизни, процесс жизни, виртуальное пространство, интернет-социализация, виртуальная личность, виртуальность, вовлеченность, направленность

Для циттирования: Зекерьяев Р.И. Эмпирическое исследование влияния ценностно-смысловой сферы личности на ее виртуальный образ: компонент смысложизненных ориентаций // Вестник Костромского государственного университета. Серия: Педагогика. Психология. Социокинетика. 2021. Т. 27 , № 1. C. 46-52. https://doi.org/10.34216/2073-1426-2021-27-1-46-52

Research Article

\section{EMPIRICAL STUDY OF THE INFLUENCE OF THE VALUE-SENSE SPHERE OF A PERSONALITY ON ITS VIRTUAL IMAGE: A COMPONENT OF MEANINGFUL ORIENTATIONS}

Ruslan I. Zekeryaev, Crimean Engineering and Pedagogic University, Simferopol, Crimea, rzekeryayev@ inbox.ru, https://orcid.org/0000-0001-8594-127X

Abstract. The article devoted to the study of the influence of the value-semantic sphere of an individual, namely, life-sense orientations, on its virtual image in the Internet space. The article provides a critical analysis of the literature devoted to the study of the value-semantic sphere of personality and virtual personality in the Internet space. It was determined that the value-semantic sphere as a complex dynamic construct of the personality determines its inner world and sets the vector of its activity. Also, during the analysis of the literature, it was revealed that the system of meanings and values determines the choice of behavioural patterns of the personality, and also acts as a censor to assess the events and phenomena that it encounters. The study analysed the virtual personality of an Internet user as a psychological phenomenon; it describes such properties of a virtual personality as virtuality (the degree of acceptance of virtual reality as an environment in which social life is feasible), involvement (the level of knowledge of information and computer technologies and a sense of belonging to a virtual society) and orientation (the presence or absence of ideas about socially approved behaviour in Internet society). The article also analyses the results of an empirical study of the influence of the component of the meaning-life orientations of the value-semantic sphere of the individual on the properties of his virtual image. It was determined that there is a direct connection between the indicator of the life process and the level of involvement of the virtual personality (people with the perception of their life as filled with meaning and emotionally saturated in the Internet space have developed motivation for life activity) and that there is a direct connection between the indicator of the result of life and the level of orientation of the virtual personality (people with a subjectively assessed high level of self-realisation in the Internet space show a tendency towards normative behaviour). 
Keywords: value-semantic sphere of personality, life-meaning orientations, result of life, process of life, virtual space, Internet socialisation, virtual personality, virtuality, involvement, orientation

For citation: Zekeryaev R. I. Empirical study of the influence of the value-sense sphere of a personality on its virtual image: a component of meaningful orientations. Vestnik of Kostroma State University. Series: Pedagogy. Psychology. Sociokinetics, 2021, vol. 27, № 1, pp. 46-52. (In Russ.). https://doi.org/10.34216/2073-1426-202127-1-46-52

$\mathrm{H}$ а данном этапе своего развития современное общество все больше подвергается виртуализации, при этом ключевой площадкой для данного процесса становится гиперреальность сети Интернет. Будучи принципиально новым информационно-коммуникативным пространством, виртуальная среда открывает широкий спектр возможной деятельности, в том числе и социального взаимодействия, как для отдельных индивидов, так и целых групп. В процессе виртуализации и перехода из реального мира в гиперреальность сети Интернет с личностью происходит ряд трансформаций, проявляющихся в модификации и расширении ее системы ценностей и смыслов, что приводит к формированию новых поведенческих и мировоззренческих паттернов. Несмотря на большое количество научных работ, посвященных процессу интернет-социализации, остается открытым вопрос о факторах, провоцирующих подобные трансформации, и, в частности, о влиянии ценностно-смысловой сферы реальной личности на ее виртуальный образ в сети Интернет.

Целью статьи является представление результатов исследования психологических особенностей компонента смысложизненных ориентаций в структуре ценностно-смысловой сферы личности на ее виртуальный образ.

Ценностно-смысловая сфера личности представляет собой комплексный динамический конструкт личности, который определяет ее внутренний мир и задаёт вектор ее деятельности. Система смыслов и ценностей детерминирует такие психологические особенности социальной активности человека, как основное содержание, вектор направленности, смысловое наполнение. Они в свою очередь регулируют поведенческие паттерны личности, а также выступают в роли цензора для оценки событий и явлений, с которыми она сталкивается.

Н.Ф. Наумова, исследуя смыслы и ценности личности, отмечала, что они являются ведущей детерминантой целеполагания. Также, по мнению ученой, ценностно-смысловая сфера выполняет ориентационную функцию в социальных процессах, в которых участвует личность, конструируя при этом ее мировоззренческую картину, обладающую свойствами целостности, осмысленности, непротиворечивости и систематизированности. Н.Ф. Наумова также говорила о том, что система смыслов и ценностей детерминирует базис для принятия решений на основе существующих субъективно значимых альтернативных вариантов, а также конструирования поведенческих границ и самого процесса активности [Наумова: 87].
Ряд ученых определял ценностно-смысловую сферу как перманентную, носящую социальный характер, направленность личности на цели, которые представляют для нее субъективную значимость и наделяются определенными смыслами. По их мнению, система смыслов и ценностей не только формирует цели человека, но также определяет способы для их реализации, подкрепляемые психологическими свойствами личности и ее поведения, являющихся резистентными по отношению к внешним социальным влияниям. Ученые отмечали, что, несмотря на свою устойчивость, ценностно-смысловая сфера личности является динамичным конструктом, который позволяет проявляться своим свойствам с учетом потребностей в каждой конкретной ситуации, модифицируя и выстраивая поведенческие паттерны для достижения актуальной цели [Алексеева, Ржанова; Журавлева: 47; Каширский: 126].

Д.А. Леонтьев, исследуя ценностно-смысловую сферу личности, отмечал, что она является образованием на пересечении мировоззренческих установок личности и ее мотивационных ориентаций. По мнению исследователя, смыслы и ценности представляют собой регуляторы социальной активности личности, а также конструируют у нее образ восприятия себя как совокупности субъективно значимых черт и особенностей. Д.А. Леонтьев также говорил о том, что индивидуальные ценности формируются на основе субъективно пережитого жизненного опыта и представляют собой систему выборочно интернализированных из общесоциальных смыслов и ценностей элементов [Леонтьев: 13].

Некоторые ученые отмечали, что ценностносмысловая сфера личности обладает иерархической динамичной структурой, проявляющейся в двух направлениях: горизонтальном (определяющем степень значимости и принятия тех или иных ценностей и смыслов) и вертикальном (взаимосвязь индивидуальных ценностей и смыслов с конструктом ценностей и смыслов социума, в котором функционирует человек). При этом учеными отмечается, что ценностно-смысловая сфера сформирована в виде трехуровневого конструкта: на первом уровне находятся абстрактные и обобщенные ценности, относящиеся к материальному и духовному миру; второй уровень включает в себя ценности, которые представляют собой психологические особенности личности, закрепленные в ее активности и деятельности; на третьем уровне находятся наиболее предпочитаемые поведенческие паттерны человека, с по- 
мощью которых он реализует свои потребности и цели [Алишев: 67; Бубнова: 144].

Виртуальная личность интернет-пользователя это сложное образование, формирующееся при переходе реальной личности в социокультурное пространство интернета, с последующей интеграцией в него и интернализацией ценностей и смыслов виртуального социума.

И.Н. Блохин в процессе исследования феномена виртуальной личности выделил их типы в зависимости от предпочитаемого стиля поведения в сети Интернет: потребители, авторы, коммуникаторы и потребители. По мнению исследователя, основной деятельностью потребителя является накопление социокультурного опыта виртуального пространства через процесс интернализации его ценностей и смыслов. И.Н. Блохин определял тип коммуникатора как человека, считающего наиболее значимой ценностью виртуального пространства возможность социального взаимодействия с другими интернет-пользователями. Под авторами исследователь понимал тип поведения в сети Интернет, заключающийся в создании уникального контента и размещения его на соответствующих ресурсах. Ученый также определял тип навигатора как личность, предпочитающую деятельность в виртуальном пространстве, связанную с оперированием информационными потоками, а также аналитикой деятельности прочих вышеописанных типов [Блохин: 125].

Некоторые ученые отмечали, что гиперреальность виртуального пространства создает новые нормы, что детерминирует формирование принципиально новой культуры. В ходе интернет-социализации ценностно-смысловая сфера личности становится диффузной и включает в себя ценности и смыслы, приобретенные в реальном пространстве и интернализированные в виртуальной среде. Сеть Интернет предоставляет возможность войти в социальную среду, идентичную реальному миру, создавать в ней новые образы для реализации потребности в самопрезентации. Процесс интернетсоциализации, выступая в роли части процесса социализации в глобальном понимании, позволяет личности создавать новые социальные связи, отыгрывать новые социальные роли и интегрироваться в референтные группы, недоступные ей в реальном пространстве. Вхождение в виртуальный социум амбивалентно: с одной стороны, оно формирует у личности осознание о неполноте социального опыта и нереализованности потенциала креативности, но, с другой стороны, предоставляет требуемые ресурсы для компенсации этой неполноты [Зекерьяев 2019а: 31; Лучинкина: 59].

3.С. Завьялова, описывая процесс конструирования виртуального образа, отмечала схожесть его этапов с процессом самоидентификации личности в реальном пространстве, выделяя ряд его этапов. По мнению ученой, на первом этапе личность ин- тегрируется в виртуальную реальность и находится в ситуации противопоставления себя ей. На следующем этапе человек выбирает себе имя в сети Интернет, что детерминирует процесс виртуальной самоидентификации личности. Последний этап, по мнению исследовательницы, начинается, когда человек начинает проявлять коммуникативную активность в виртуальном социуме, который выбирает самостоятельно, опираясь на свои субъективные предпочтения и ценностно-смысловую сферу [Завьялова: 38].

Ряд исследователей феномена виртуальной реальности отмечали ее специфику и ряд отличительных признаков от реального пространства: анонимность, физическую непредставленность, единовременность разных видов деятельности, отсутствие регламентированности взаимодействия и поведения и т. д. Вступая в социальное взаимодействие, виртуальная личность не присутствует физически в данном процессе, а также в любой момент может его завершить. Данные особенности процесса коммуникации в сети Интернет детерминируют стремление личности экспериментировать со своим виртуальным образом, приближая его к «Я-идеальному». Данное явление может также возникать как способ компенсации психологических проблем реального пространства, а также как стремление к самовыражению через отыгрывание различных социальных ролей [Белинская: 127; Зекерьяев 2019б: 255].

А.И. Лучинкина, исследуя виртуальную личность как психологический феномен, выделяла три ее свойства, такие как виртуальность, вовлеченность и направленность. Под виртуальностью исследовательница понимала степень принятия виртуальной реальности как среды, в которой осуществима социальная жизнедеятельность. Так, по ее мнению, чем выше уровень виртуальности, тем больше мотивация человека к пребыванию в сети Интернет, которая воспринимается как более предпочитаемая среда для времяпровождения, чем реальное пространство. А.И. Лучинкина определяла вовлеченность как уровень владения информационно-компьютерными технологиями и ощущение принадлежности к виртуальному социуму. Чем выше, по мнению ученой, уровень вовлеченности, тем больше человек считает себя частью социокультурного пространства сети Интернет и тем больше он мотивирован к пребыванию в виртуальной среде. А.И. Лучинкина под направленностью понимала наличие или отсутствие представлений о социально одобряемом поведении в интернет-социуме. По мнению исследовательницы, чем выше уровень направленности, тем больше стремление личности следовать правилам и нормам, выдвигаемым по отношению к нему виртуальной социокультурной средой, в которой она находится [Лучинкина, Юдеева, Ушакова: 72]. 
Эмпирическую базу пилотного исследования составили 300 человек с разными уровнями интернет-активности. Возрастное и гендерное распределение респондентов: 150 мужчин и 150 женщин в возрасте от 18 до 35 лет. Респонденты привлекались благодаря рассылке приглашений к участию в исследовании и были выбраны методом случайных чисел.

В ходе исследования использовался ряд методик:

1. Опросник «Личность в интернет-пространстве» А.И. Лучинкиной для определения уровня интернет-активности личности.

2. Методика «Тест смысложизненных ориентаций» Д.А. Леонтьева.

На первом этапе исследования с помощью методики «Личность в интернет-пространстве» А.И. Лучинкиной было определено процентное распределение респондентов по уровням их виртуальности, вовлеченности и направленности (рис. 1-3).
На следующем этапе был проведен корреляционный анализ между показателями свойств виртуальной личности респондентов и уровнями их смысложизненных ориентаций в структуре ценностно-смысловой сферы.

Значимые корреляционные связи представлены в таблице 1.

Из таблицы 1 видно, что существует прямая связь между показателем процесса жизни и уровнем вовлеченности виртуальной личности (коэффициент r-Пирсона $=0,767)$. Данная связь проявляется в том, что у людей с восприятием своей жизни как наполненной смыслом и эмоционально насыщенной в интернет-пространстве развита мотивация к жизнедеятельности. Они воспринимают себя как полноценных участников сетевой культуры, обладают высокой инструментальной компетентностью. Также у таких респондентов наблюдается стремление проводить время в интернет-пространстве и коммуницировать с други-

Виртуальность

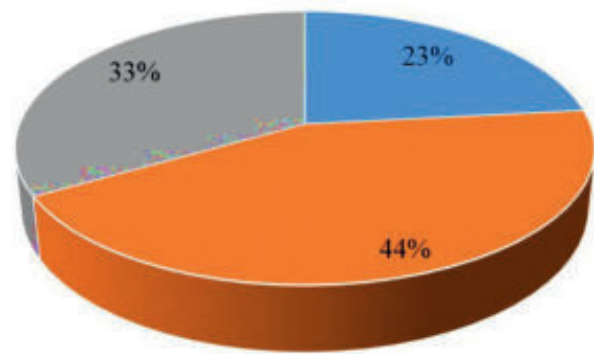

= низкий уровень

- средний уровень

" высокий уровень

Рис. 1. Процентное распределение респондентов по уровню виртуальности

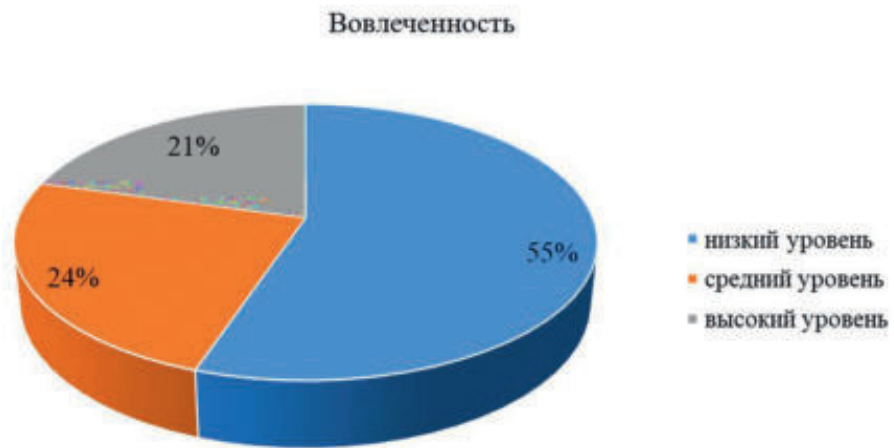

Рис. 2. Процентное распределение респондентов по уровню вовлеченности

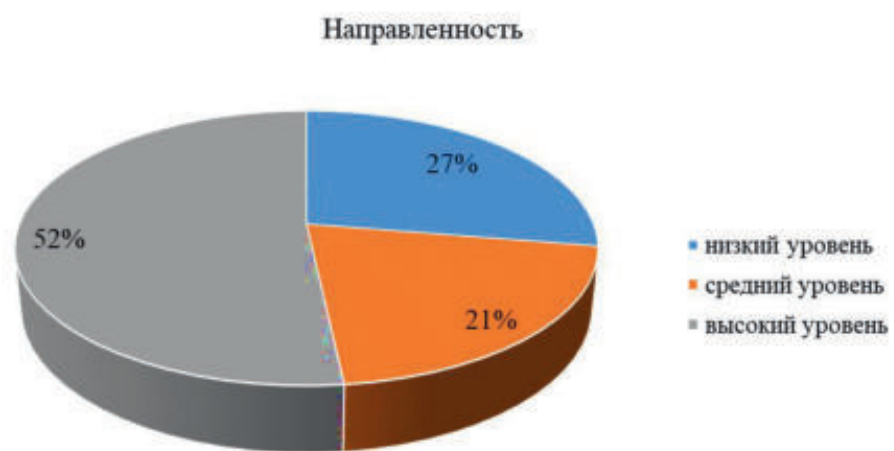

Рис. 3. Процентное распределение респондентов по уровню направленности 
Таблица 1

Значимые корреляционные связи

\begin{tabular}{|c|c|c|c|c|c|}
\hline & & Вовлеченность & Направленность & Результат жизни & Процесс жизни \\
\hline \multirow{3}{*}{ Вовлеченность } & Корреляция Пирсона & 1 & $-0,362 * *$ & $-0,141 *$ & $0,767^{*}$ \\
\hline & Знач. (двухсторонняя) & & 0,000 & 0,014 & 0,000 \\
\hline & $\mathrm{N}$ & 300 & 300 & 300 & 300 \\
\hline Направленность & Корреляция Пирсона & $-0,362 * *$ & 1 & $0,732 * *$ & $-0,144 *$ \\
\hline \multirow{3}{*}{ Результат жизни } & Корреляция Пирсона & $-0,141^{*}$ & $0,732 * *$ & 1 & $-0,009$ \\
\hline & Знач. (двухсторонняя) & 0,014 & 0,000 & & 0,881 \\
\hline & $\mathrm{N}$ & 300 & 300 & 300 & 300 \\
\hline Процесс жизни & Корреляция Пирсона & $0,767 * *$ & $-0,144^{*}$ & $-0,009$ & 1 \\
\hline
\end{tabular}

Примечание: * - корреляция значима на уровне 0,05 (двухсторонняя); ** - корреляция значима на уровне 0,01 (двухсторонняя)

Таблица 2

Результат применения критерия Краскелла - Уоллиса для показателей процесса жизни и уровня вовлеченности в виртуальном пространстве

\begin{tabular}{||l|c|}
\hline & Процесс жизни \\
\hline \hline Хи-квадрат & 153,286 \\
\hline Ст. св. & 2 \\
\hline Асимптотическая значимость & 0,000 \\
\hline
\end{tabular}

Таблица 3

Результат применения критерия Краскелла - Уоллиса для показателей результата жизни и уровня направленности в виртуальном пространстве

\begin{tabular}{||l|c|}
\hline & Результат жизни \\
\hline \hline Хи-квадрат & 218,868 \\
\hline Ст. св. & 2 \\
\hline Асимптотическая значимость & 0,000 \\
\hline
\end{tabular}

ми участниками виртуального социума. И наоборот, при восприятии респондентами собственной жизни как бессмысленной в виртуальном пространстве наблюдается ощущение изоляции и нежелание без крайней нужды входить в социокультурную среду сети Интернет.

Существенная разница в проявлении процесса жизни у респондентов с различными уровнями вовлеченности также может быть обоснована результатами применения критерия Краскелла - Уоллиса, в которых уровень ассимптотической значимости $=0,000<0,005$ (табл. 2).

Из таблицы 1 видно, что существует прямая связь между показателем результата жизни и уровнем направленности виртуальной личности (коэффициент r-Пирсона = 0,732). Данная связь проявляется в том, что у людей с субъективно оцениваемым высоким уровнем самореализации в интернет-пространстве проявляется склонность к нормативному поведению. Такие респонденты отмечали желание соблюдать правила и нормы, предписываемые виртуальными сообществами. И наоборот, при низком показателе результата жизни респонденты чувствуют свой потенциал нереализованным и пытаются компенсировать это ощущение в сети Интернет. При этом для достижения данной цели они склонны нарушать правила коммуникации, выдвигаемые виртуальным социумом.

Существенная разница в проявлении результата жизни у респондентов с различными уровнями направленности также может быть обоснована результатами применения критерия Краскелла - Уоллиса, в которых уровень ассимптотической значимости $=0,000<0,005$ (табл. 3).

Таким образом, исходя из результатов корреляционного анализа и использования критерия Краскелла - Уоллиса можно сделать вывод о том, что существует связь между показателем процесса жизни и уровнем вовлеченности в виртуальном пространстве, а также показателем результата жизни и уровнем направленности в виртуальном пространстве.

Выводы. Ценностно-смысловая сфера личности представляет собой комплексный динамический 
конструкт личности, который определяет ее внутренний мир и задаёт вектор деятельности. Система смыслов и ценностей детерминирует такие психологические особенности социальной активности человека, как основное содержание, вектор направленности, смысловое наполнение. Они, в свою очередь, регулируют поведенческие паттерны личности, а также выступают в роли цензора для оценки событий и явлений, с которыми она сталкивается.

Существует прямая связь между показателем процесса жизни и уровнем вовлеченности виртуальной личности. Данная связь проявляется в том, что у людей с восприятием своей жизни как наполненной смыслом и эмоционально насыщенной в интернет-пространстве развита мотивация к жизнедеятельности. Существует прямая связь между показателем результата жизни и уровнем направленности виртуальной личности. Данная связь проявляется в том, что у людей с субъективно оцениваемым высоким уровнем самореализации в интернет-пространстве проявляется склонность к нормативному поведению.

\section{Список литературы}

Алексеева О.С., Ржанова И.Е. Ценности и их связь с базовыми чертами личности // Психологические исследования. 2019. № 12 (63). URL: http://psystudy.ru/index.php/num/2019v12n63/1677alekseeva63.html (дата обращения: 8.09.2020)

Алишев Б.С. Психологическая теория ценности: системно-функциональный подход: дис. ... докт. психол. наук. Казань, 2002. 367 с.

Белинская Е.П. Идентичность личности в условиях социальных изменений: дис. ... докт. психол. наук. М., 2006. 479 с.

Блохин И.Н. Политическое поведение личности в медиасреде // Гуманитарный вектор. Серия: История, политология. 2013. № 3 (35). С. 125-134.

Бубнова С.C. Методика диагностики индивидуальной структуры ценностных ориентаций // Методы психологической диагностики. 1994. Т. 2. C. 144-157.

Журавлева Н.А. Динамика ценностных ориентаций личности в условиях социально-экономических изменений: дис. ... канд. психол. наук. М., 2002. 228 c.

Завьялова 3.С. Идентификация личности в условиях сетевых коммуникаций: постановка проблемы // Гуманитарная информатика. 2008. Вып. 4. C. $38-50$.

Зекерьяев Р.И. Психологические особенности виртуальной личности пользователя и ее типы // Современная наука: актуальные проблемы теории и практики. Серия: познание. 2019. № 1 (88). C. 31-37.

Зекерьяев Р.И. Типы виртуальной личности интернет-пользователя // Ученые записки: электрон. науч. журнал Курского гос. ун-та. 2019. № 1 (49). C. 255-263.
Каширский Д.В. Психология личностных ценностей: дис. ... докт. психол. наук. М., 2014. 551 с.

Леонтьев Д.А. Ценностные представления в индивидуальном и групповом сознании: виды, детерминанты и изменения во времени // Психологическое обозрение. 1998. № 1. С. 13-25.

Лучинкина А.И., Юдеева Т.В., Ушакова В.Р. Информационно-психологическая безопасность личности в интернет-пространстве. Симферополь: ДИАЙПИ, 2015. $151 \mathrm{c.}$

Лучинкина А.И. Специфика интернета как института социализации // Научный результат. Педагогика и психология образования. 2019. № 1. C. 59-69.

Наумова Н.Ф. Социологические и психологические аспекты целенаправленного поведения. М.: Наука, 1988. 200 с.

\section{References}

Alekseeva O.S., Rzhanova I.E. Tsennosti $i$ ikh svyaz's bazovymi chertami lichnosti [Values and their connection with basic personality traits]. Psikhologicheskiye issledovaniya [Psychological research], 2019, № 12 (63). URL: http://psystudy. ru/index.php/num/2019v12n63/1677-alekseeva63. html (access date: 09.08.2020). (In Russ.)

Alishev B.S. Psikhologicheskaya teoriya tsennosti: Sistemno-funktsional'nyy podkhod: dis. ... dokt. psikhol. nauk [Psychological theory of value: Systemfunctional approach]: dis. doct. psychol. sciences. Kazan, 2002, 367 p. (In Russ.)

Belinskaya E.P. Identichnost' lichnosti v usloviyakh sotsial'nykh izmeneniy: dis. ... dokt. psikhol. nauk [Identity of personality in conditions of social changes]. Moscow, 2006, 479 p. (In Russ.)

Blokhin I.N. Politicheskoye povedeniye lichnosti $v$ mediasrede [Political behavior of the individual in the media environment]. Gumanitarnyy vektor. Seriya: Istoriya, politologiya [Humanitarian vector. Series: History, Political Science], 2013, № 3 (35), pp. 125134. (In Russ.)

Bubnova S.S. Metodika diagnostiki individual'noy struktury tsennostnykh oriyentatsiy [Methods of diagnostics of the individual structure of value orientations]. Metody psikhologicheskoy diagnostiki [Methods of psychological diagnostics], 1994, vol. 2, pp. 144-157. (In Russ.)

Zhuravleva N.A. Dinamika tsennostnykh oriyentatsiy lichnosti $v$ usloviyakh sotsial'noekonomicheskikh izmeneniy: dis. ... kand. psikhol. nauk. [Dynamics of personal value orientations in conditions of socio-economic changes]. Moscow, 2002, 228 p. (In Russ.)

Zavyalova Z.S. Identifikatsiya lichnosti $v$ usloviyakh setevykh kommunikatsiy: postanovka problemy [Personal identification in the context of network communications: problem statement]. Gumanitarnaya informatika [Humanitarian informatics], 2008, issue 4, pp. 38-50. (In Russ.) 
Zekeryaev R.I. Psikhologicheskiye osobennosti virtual'noy lichnosti pol'zovatelya $i$ yeye tipy [Psychological features of the user's virtual personality and its types]. Sovremennaya nauka: aktual'nyye problemy teorii $i$ praktiki. Seriya: poznaniye [Modern science: actual problems of theory and practice. Series: Cognition], 2019, № 1 (88), pp. 31-37. (In Russ.)

Zekeryaev R.I. Tipy virtual'noy lichnosti internetpol'zovatelya [Types of virtual personality of the Internet user]. Uchenyye zapiski. Elektronnyy nauchnyy zhurnal kurskogo gosudarstvennogo universiteta [Scientific notes. Electronic scientific journal of Kursk State University], 2019, № 1 (49), pp. 255-263. (In Russ.)

Kashirsky D.V. Psikhologiya lichnostnykh tsennostey: dis. ... dokt. psikhol. nauk [Psychology of personal values]. Moscow, 2014, 551 p. (In Russ.)

Leont'ev D.A. Tsennostnyye predstavleniya $v$ individual'nom $i$ gruppovom soznanii: vidy, determinanty $i$ izmeneniya vo vremeni [Value representations in individual and group consciousness: types, determinants and changes in time]. Psikhologicheskoye obozreniye [Psychological review], 1998, № 1, pp. 13-25. (In Russ.)
Luchinkina A.I., Yudeeva T.V., Ushakova V.R. Informatsionno-psikhologicheskaya bezopasnost lichnosti $v$ internet-prostranstve [Information and psychological security of the individual in the Internet space]. Simferopol, DIAIPI Publ., 2015, 151 p. (In Russ.)

Luchinkina A.I. Spetsifika interneta kak instituta sotsializatsii [Specificity of the Internet as an institution of socialization]. Nauchnyy rezul'tat. Pedagogika $i$ psikhologiya obrazovaniya [Scientific result. Pedagogy and psychology of education], 2019, № 1, pp. 59-69. (In Russ.)

Naumova N.F. Sotsiologicheskiye $i$ psikhologicheskiye aspekty tselenapravlennogo povedeniya [Sociological and psychological aspects of purposeful behavior]. Moscow, Nauka Publ., 1988, 200 p. (In Russ.)

Статья поступила в редакциюо 24.11.2020; одобрена после речензирования 13.01.2021; принята к публикации 26.02.2021.

The article was submitted 24.11.2020; approved after reviewing 13.01.2021; accepted for publication 26.02.2021. 